\title{
Effect of the industrial wastes purification system on the productivity of the yeast factory Lesaffre in Wolczyn
}

\author{
Andrzej Gawdzik, Barbara Włodarczyk \\ University of Opole, Department of Process Engineering, st.Dmowskiego 7-9,45-365 Opole,Poland
}

\begin{abstract}
The purpose of this work is to present that rearrangement of the industrial wastes purification system may cause the growth of the productivity. The analysis presented deals with the yeast factory Lesaffre in Wolczyn (Poland). Most of the industrial wastes (JW) produced there are utilized in agricultural fields (AF) but part of them is pre-treated in an evaporator battery (EB). The basic parameter determining amount of the JW to be utilized in the AF is nitrogen concentration for this element in excess can lead to destruction of plants. At present only the JW coming out from the first two separators are directed to the EB in the factory. In order to increase the yeast productivity of the factory one has proposed to send additionally to the ES a certain part $\mathrm{n}$ of the JW stream coming out from the third centrifugal separator. Results presented in this paper show that running in this way the system of JW purification may cause the increase in the yeast productivity in the factory even of the value of $60 \%$.
\end{abstract}

Keywords: yeast; nitrogen; productivity; system; agricultural fields.

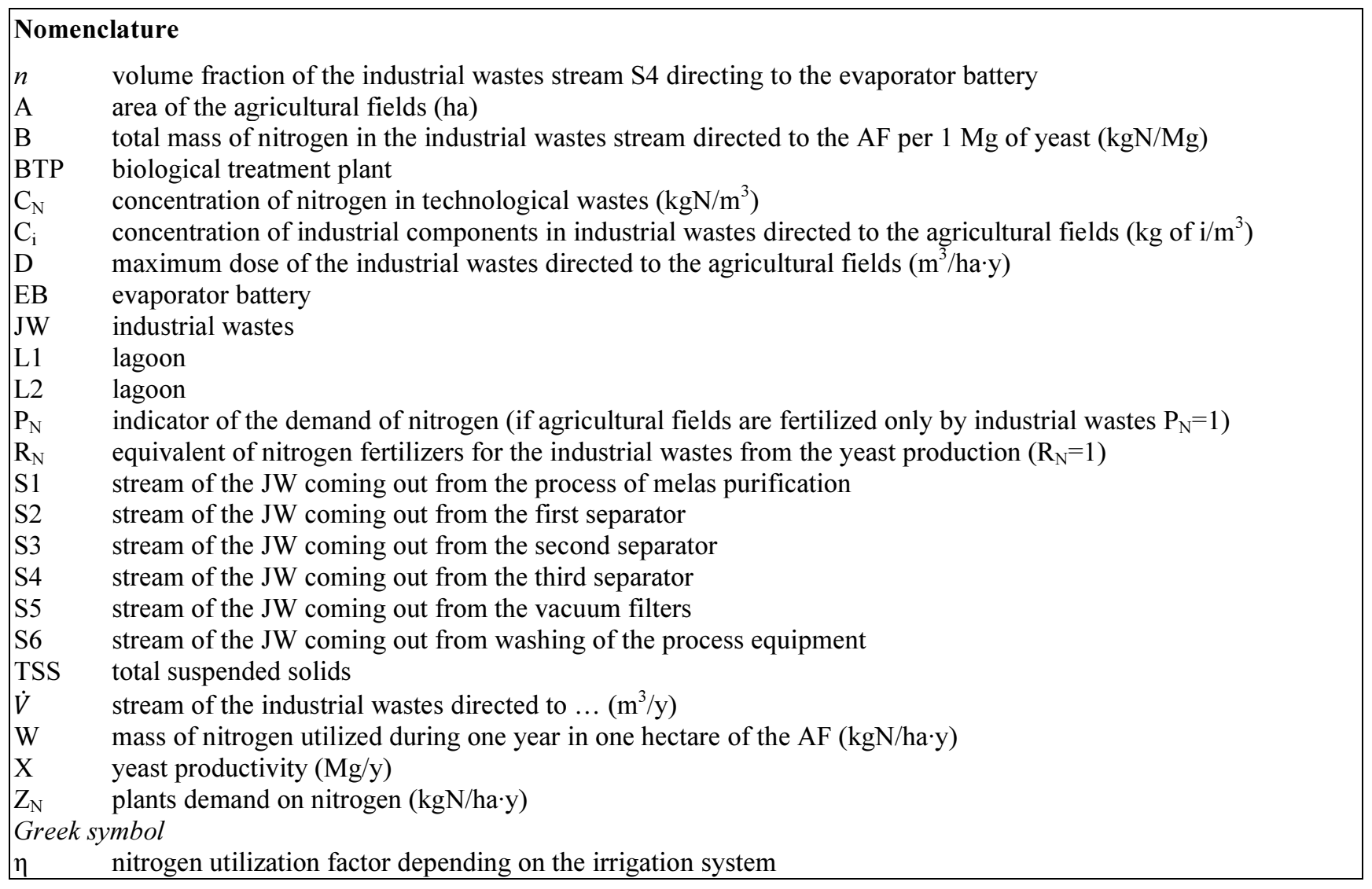

Corresponding author: Andrzej Gawdzik. E-mail address: kip@uni.opole.pl

http://dx.doi.org/10.3846/enviro.2014.020

(C) 2014 The Authors. Published by VGTU Press. This is an open-access article distributed under the terms of the Creative Commons Attribution License, which permits unrestricted use, distribution, and reproduction in any medium, provided the original author and source are credited. 


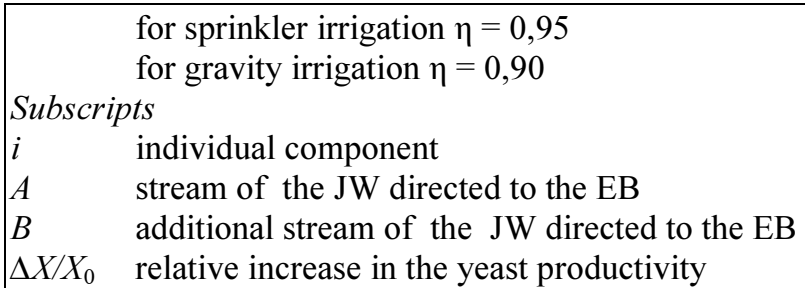

\section{Analysis of the industrial wastes purification system existing in the yeast factory Lesaffre}

The essential feature of the food industry is a large amount of industrial wastes. Most of them are suitable for transformation into raw materials for other technologies. This way we can reduce their negative impact on the environment and use them as a new source of raw materials. An example of such a solution is the yeast industry. Industrial wastes from this industry may be used as fertilizers, which may resulting recovery of macro and micronutrients as well as an organic matter. The latter one is very important on account of the deficit an organic matter in the soils of Europe [1-4]. Industrial wastes from the yeast production process may be used directly or as a concentrated in an evaporation station fertilizer. The yeast industry wastes are strongly polluted. The main parameters polluting technological sewages are nitrogen, potassium, total suspension, BDO, CDO, etc. Such wastes are mostly utilized in agricultural fields (AF). Unfortunately, these fields may only accept a limited amount of wastes. The basic parameter limiting the amount of industrial wastes to be utilized there is nitrogen contents for this element in excess can lead to destruction of plants [5-7].

Volume of the industrial wastes which may be utilized during one year in one hectare of the AF may be described by the following equation.

$$
D=\frac{Z_{N} \cdot P_{N}}{C_{N f} \cdot \eta \cdot R_{N}}
$$

For a steady field culture of plants in the AF all quantities in Eqn (1) are constant, except the concentration of nitrogen $C_{N f}$ and so this equation may be written in the form:

$$
D=\frac{W}{C_{N f}}
$$

The value of $W$ in Eqn (2) determines the mass of nitrogen which may be utilized during one year in one hectare of the AF. Then the mass of nitrogen which may be utilized in one year in the AF is described by the Eqn (3)

$$
M=W \cdot A
$$

If the system of purification of the industrial wastes consists only of the $\mathrm{AF}, A_{\text {min }}$, their area determines the capacity of the yeast production of such a factory. The value of this capacity may be calculated as follows:

$$
X=\frac{M}{B}
$$

It is also easy to determine such value of the area of the AF which ensures the expected productivity $X$ of this yeast factory. Combination of the Eqns (3-4) leads to the following result:

$$
A_{\min }=\frac{B}{W} \cdot X
$$

If the area of the AF belonging to the yeast factory being now under consideration, is smaller than the value of $A_{m i n}$, given by Eqn (5), the expected productivity will not be achieved.

The scheme at the purification system of the industrial wastes existing in the yeast factory Lesaffre in Wolczyn is shown in Fig. 1.

This system consists of evaporator battery (EB), agricultural fields (AF) and biological treatment plant (BTP).

It is possible for simplication of the further considerations, to assume that this system consists only of the agricultural fields and the evaporator battery (EB). In such a case the expected yeast productivity $X$ is not only the function of the area of the AF belonging to the factory, because a certain part of the industrial wastes may be utilized in the EB. So, for the limited area of the AF the capacity of yeast production tied with the AF may be calculated from the following equation:

$$
X_{A F}=\frac{W}{B} \cdot A
$$

Further increase in the capacity of the yeast production in the factory may be achieved by increasing in the amount of the industrial wastes being supplied to the evaporator battery.

The main sources of the industrial wastes in the yeast factory Lesaffre are three centrifugal separators. Nowadays, only the wastes coming out from the first two separators, streams $S 2$ and $S 3$, are sent to the evaporator battery, while the wastes coming out from the third separator, stream $S 4$, are not sent there as they contain less pollutants. 


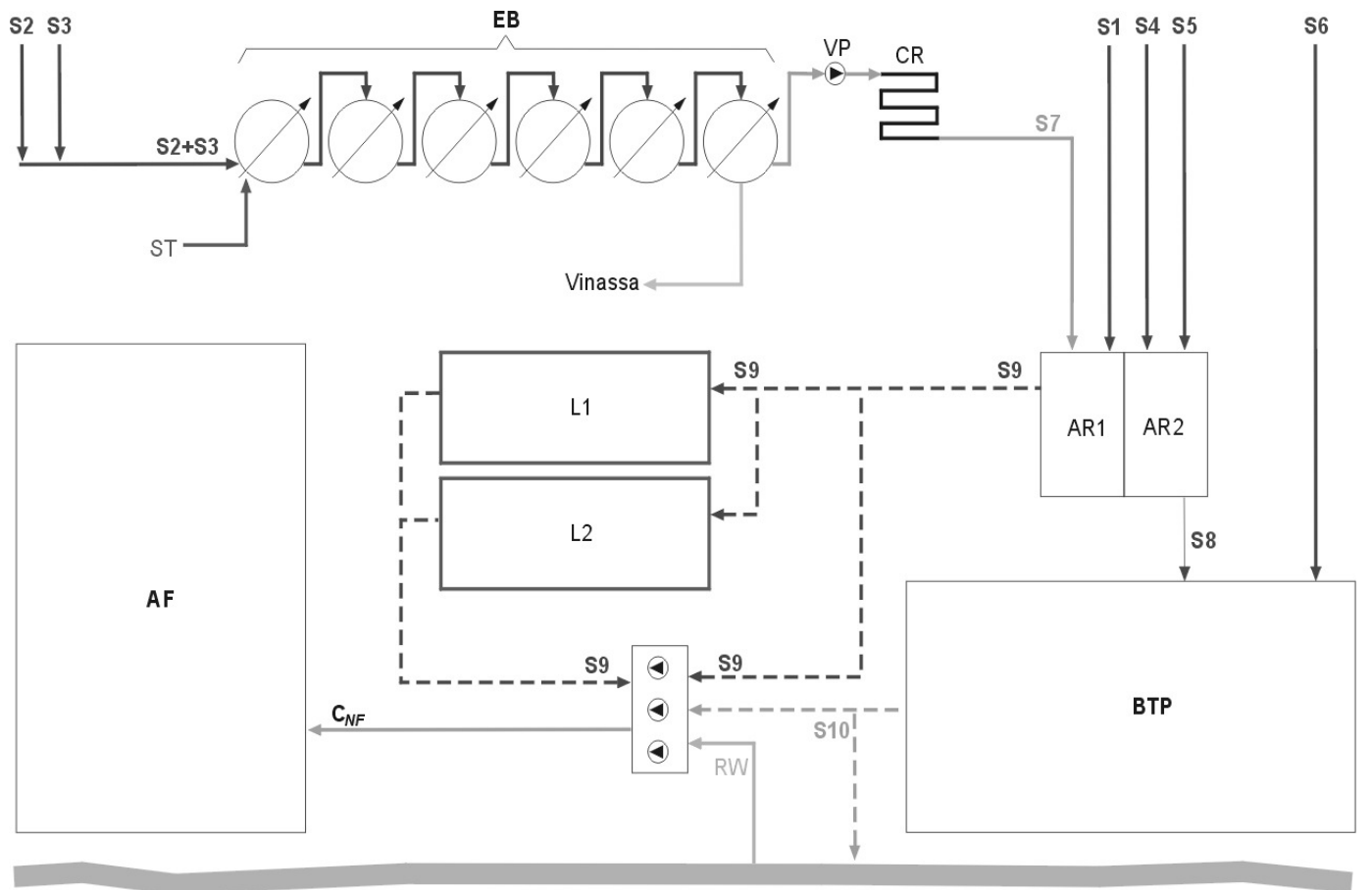

Fig. 1. Scheme of the industrial wastes purification system in the yeast factory Lesaffre in Wolczyn

Nevertheless, directing a certain part $n$ of the industrial wastes stream $S 4$ to the evaporator battery will enable a further reduction of all pollutants concentration and in consequence the increase both the maximum volume of the industrial wastes distributed in the $\mathrm{AF}$ in one year and the yeast production capacity.

Such modification of the industrial wastes purification system, existing in the yeast factory Lesaffre in Wolczyn is presented in Fig. 2.

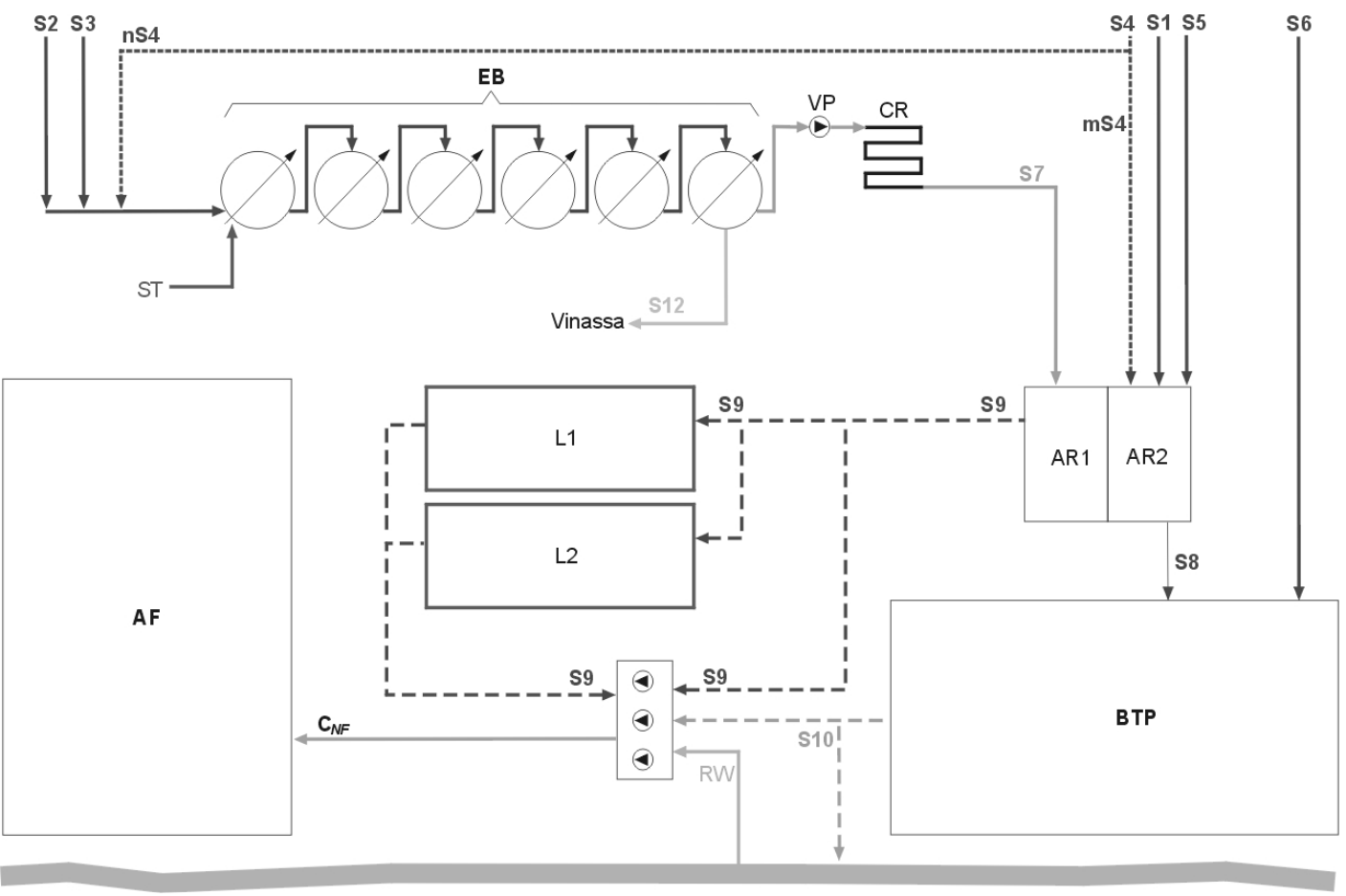

Fig. 2. Modification of the industrial wastes purification system existing in the yeast factory Lesaffre in Wolczyn

Directing an additional stream of the industrial wastes $n \cdot S 4$ to the pre-cleaning in the evaporator battery will reduce concentrations of all components to the following values:

$$
C_{i}=\frac{(1-n) \dot{V}_{B} C_{i B}+\dot{V}_{A} C_{i A}}{\dot{V}_{S}}
$$


Decrease in components concentration in the industrial wastes stream $S_{11}$ coming in the AF versus the volume fraction $n$ is presented in Fig. 3.

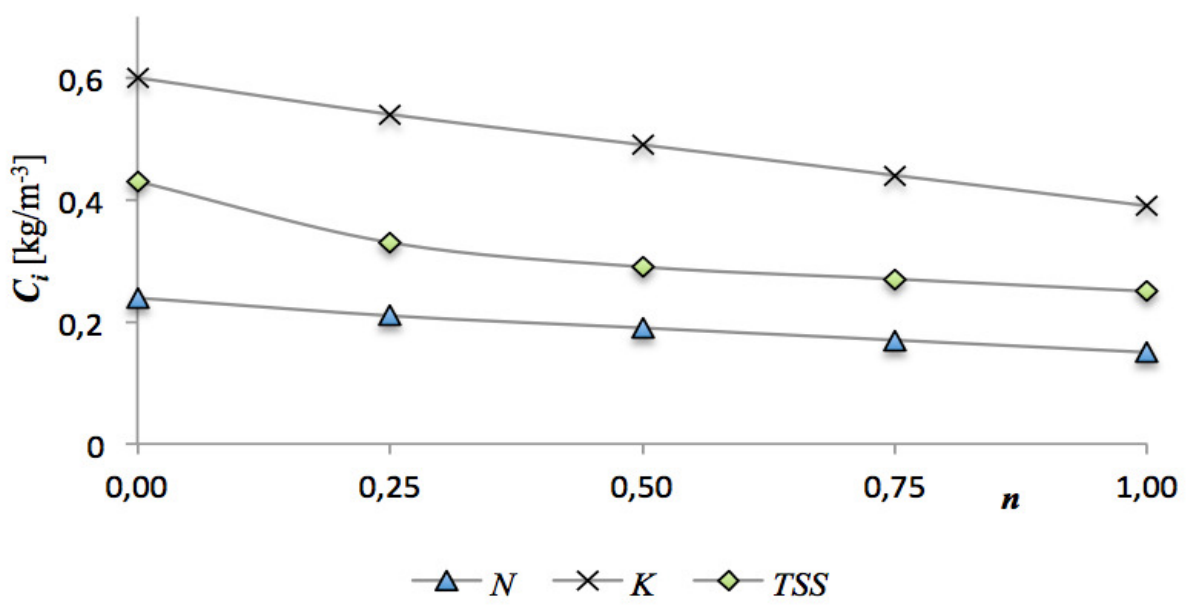

(a)

(b)

Fig. 3. Decrease in component concentration in the wastes stream $S_{11}$ versus the volume fraction

Capacity of the yeast production is determined by the concentration of nitrogen in the industrial wastes stream $S_{11}$ which is supplied to the AF. Fig. 3. shows that increase in the volume fraction $n$ causes decrease in the nitrogen concentration $C_{N}$ what, in consequence, makes possible increase in the capacity of the yeasts production.

The relative increase in the capacity of the yeast production $\Delta X / X_{0}$ may be calculated from the following formula

$$
\frac{\Delta X}{X_{0}}=\frac{n \dot{V}_{B} C_{i B}}{(1-n) \dot{V}_{B} C_{i B}+\dot{V}_{A} C_{i A}}
$$

The relative increase in the yeast productivity $\Delta X / X_{0}$ versus the volume fraction $\mathrm{n}$ is illustrated in Fig. 4.

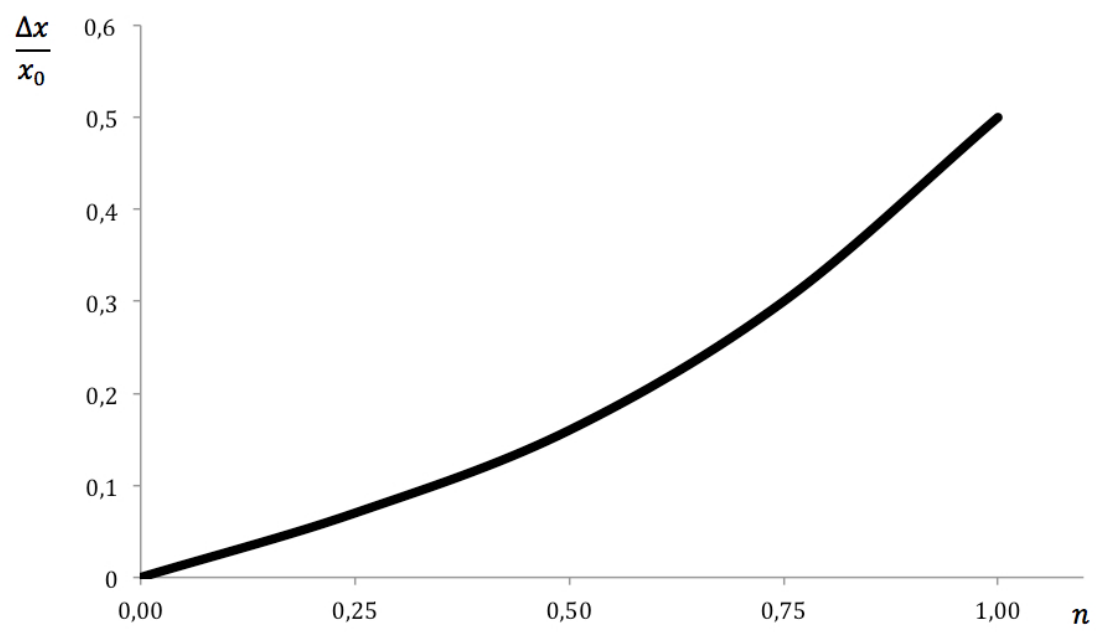

Fig. 4. Relative increase in the yeast productivity versus the volume fraction $n$

The analysis of the results presented in Fig. 4. revealed that the maximum value of the relative increase in the yeast productivity, obtained for $n=1$, is equal to $50 \%$.

Moreover, a condensate from the EB is a valuable organic fertilizer Vinassa and is sold to individual farmers. The sale of such a fertilizer covers a part of the high cost of running of the evaporator battery. On the other hand, partial replacement of natural gas by biomass in order to supply the power to the evaporator battery allows to reduce both the $\mathrm{CO}_{2}$ emission and the costs of energy consumption. In addition, the biomass grown in the AF will be fertilized by the industrial wastes from the yeast production. In the last case the maximum value of the relative increase in the yeast productivity may even reach the value of $60 \%[8-12]$. 


\section{Conclusions}

- Directing a certain part $\mathrm{n}$ of the industrial wastes stream coming out from the third separator (S4) will enable the increase in the yeast productivity. For $n=1$ this increase may even reach the value of $50 \%$

- Additionally, in the case of cultivation of the energy crops in the agricultural fields, fertilized by the industrial wastes, the increase in the yeast productivity may reach the value of $60 \%$

- The modification presented in this paper provide not only the increase in the yeast productivity but the reduction of the $\mathrm{CO}_{2}$ emission as well

\section{Acknowledgements}

The authors would like to thank dr Ryszard Błaszków the director of the plant Lesaffre in Wolczyn for a lot of advises and directions.

\section{References}

[1] Csuk, R.; Glanzer B.I. 1991. Baker's yeast mediated transformations in organic chemistry, Chem. Rev., 49-97. http://dx.doi.org/10.1021/cr00001a004 [2] Walker, G. M.. 1998. Yeast-physiology and biotechnology, ed. J. Wiley, Chichester.

[3] Włodarczyk, B.; Gawdzik ,A. 2011. Ocena gleb uprawnych na podstawie poziomu substancji nawozowych w wyniku nawożenia nawozem organicznym powstałym z przemystu drożdżowego. Monografia Uniwersytetu Opolskiego, Inżynieria Procesowa w Ochronie Środowiska, 92-100.

[4] Pawełczyk, A.; Górecki, H. 1996. Perspektywy utylizacji odpadów rolno-spożywczych na nawozy mineralno-organiczne. Politechnika Wrocławska, Wocław.

[5] Kutera, J. 1986. Wykorzystanie ścieków przemysłu spirytusowo- drożdżowego w rolnictwie. Materiały instruktażowe IMUZ nr 52. Falenty.

[6] Aparicio, I.; Santos, J. L.; Alonso, E. 2009 Limitation of the concentration of organic pollutants in sewage sludge for agricultural purposes, Waste Management 29(5): 1747-1753. http://dx.doi.org/10.1016/j.wasman.2008.11.003

[7] Wang, X.; Chen, T.; Ge, Y.; Jia, Y. 2008. Studies on land application of sewage sludge and its limiting factors, Journal of Hazardous Materials 160 : 554-558. http://dx.doi.org/10.1016/j.jhazmat.2008.03.046

[8] Wrzosek, J.; Gworek, B. 2010. Biomass as renewable energy source. Monografia Uniwersytetu Opolskiego, Ochrona Środowiska i Zasobów Naturalnych, $\mathrm{nr} 43$.

[9] Kamiński, J.; Leduc, G. 2010. Energy efficiency improvement options for the EU food industry, Polityka Energetyczna 13(1).

[10] Directive 2001/77/EC of European Parliament and of the Council on the Promotion of Electricity Produced from Renewable Energy Sources in the Internal Electicity Market.

[11] Kaltschmitt, M.; Hartmann, H. 2001. Energie aus Biomasse: Grundlagen. Techniken und Verfahren, Springer-Verlag. http://dx.doi.org/10.1016/j.jhazmat.2008.03.046

[12] Directive 2009/28/EC the European Parliament and of the Council of 23 April on the promotion of the use of energy from renewable sources and amending and subsequently repealing Directives 2001/77/EC and 2003/30/EC. 